Original Article

\title{
Frequency of Extradural Hematoma in Patients with Skull Fracture after Head Injury
}

\author{
Muhammad Ammad-ul-Haq ${ }^{1}$, Ghayur Abbas $^{2}$, Anam Ali ${ }^{1}$, Mamoona Hamid ${ }^{3}$, Daniyal Ahmed ${ }^{2}$, \\ Saad Javed ${ }^{4}$, Eesha Yaqoob ${ }^{5}$ \\ ${ }^{1}$ Rawalpindi Medical University (RMU) and Allied Hospitals, Rawalpindi, Pakistan \\ ${ }^{2}$ Al-Nafees Medical College and Teaching Hospital, Islamabad, Pakistan \\ ${ }^{3}$ Rawal Institute of Health Sciences, Islamabad, Pakistan \\ ${ }^{4} \mathrm{Al}-$ Nafees Medical College \& Hospital, Islamabad, Pakistan \\ ${ }^{4}$ Department of Neurosurgery, Holy Family Hospital, Lahore, Pakistan \\ ${ }^{5}$ Department of Sociology, Pir Mehr Ali Shah Arid Agriculture University, Rawalpindi, Pakistan
}

\section{ABSTRACT}

Objective: To assess the frequency of patients with extradural hematoma who have a skull fracture on $\mathrm{x}$-ray skull presenting with a head injury.

Material \& Methods: A descriptive case series was conducted the Department of Neurosurgery, RMU \& Allied Hospital, Rawalpindi. 322 patients fulfilling the selection criteria were enrolled in the study from Emergency Ward. Patients with head injury having skull fracture undergone a CT scan for assessment of presence or absence of extradural hematoma. CT scan was done by a single senior radiologist for all patients.

Results: Mean age of patients in this study was $41.31 \pm 14.67$ years. Among the patients 259 (80.4\%) were male and $63(19.6 \%)$ were females. The mean duration of injury of the patients was $6.37 \pm 3.40$. Extradural hematoma was diagnosed in 104 (32.3\%) patients. Age and site of fracture showed a statistically significant association for extradural hematoma. Whereas gender, duration of injury, and type of fracture did not show significant association for extradural hematoma.

Conclusion: Results of this study showed a low frequency of extradural hematoma in patients who presented with a head injury. Still, any patient suspected of head injury leading to skull fractures must be examined on CT scan to avoid and timely detect the intracranial bleeding in order to avert the complications and mortality after traumatic head injury.

Keywords: Head injury, Extradural, Hematoma, Skull, Fracture, X-ray.

Corresponding Author: Muhammad Ammad-ul-Haq RMU and Allied Hospitals, Rawalpindi

Email: ammad86@gmail.com
Date of Submission: 13-01-2021

Date of Revision: 15-03-2021

Date of Online Publishing: 26-03-2021

Date of Print: 31-03-2021

DOI: 10.36552/pjns.v25i1.504

\section{INTRODUCTION}

The skull is developed due to a combination of 
many flat bones, which join together by cranial sutures. Every flat bone is consisting of i) outer table, ii) spongy diploe, and iii) inner table. The inner table is made up of the fibrous, thick Dura mater. The narrow subdural space lies between the inner Dura surface and the thin arachnoid mater, which covers the inner brain surface. ${ }^{1-3} \mathrm{~A}$ skull fracture is defined as a break in the continuity of skull bone due to trauma, which occurs due to direct hit, road traffic accidents, or falls. Even in the absence of external fracture, the cranial contents may also be damaged due to skull deformity after localized impact. If the direct force is extreme, the skull may fracture at or close to the impact the site. Simple skull fractures can rarely lead to neurological deficits, but the associated intracranial injuries may cause serious neurological results. ${ }^{3,4}$

Hematoma inside skull in the brain, most commonly extradural hematoma, is the type of traumatic brain injury. This develops due to the accumulation of blood between layers of the dura mater and the table of the skull. The spinal cord is also covered by the layer of the dura mater, so the chances of hemorrhage in the spinal cord may also be at high risk. Normally because of trauma to the head, this situation may worsen the condition of patients, due to an increase in pressure in the intracranial region, which compresses the delicate tissues of the brain and leads to brain shift. The disorder can be detected in about one to three percent of head injuries. ${ }^{5}$

It has been estimated that extradural hematoma can be developed in ten to twenty percent of patients with head injuries. About seventeen percent of patients, who were conscious previously, can go into a coma due to the development of extradural hematoma after head trauma. In a retrospective analysis, done on the cases of extradural hematoma in the United States, by using the Nationwide Inpatient Sample. Total 5,189 cases of extradural hematoma who were admitted to the hospital were recognized, and the in-hospital complications and mortality rate were observed as $2.9 \%$ and $3.5 \%$, respectively. ${ }^{6}$

In some patients of brain injury, extradural or subdural hematoma, intracerebral bleed, or diffuse axonal injury can be observed. ${ }^{7}$ Middle meningeal artery is most commonly ruptured at the temporal bone. The Parietotemporal region is frequently involved in skull vault fractures due to decreased thickness of bone over the area. The trauma to the temporal bone may results in a tear of the temporal artery, even without evidence of fracture in the skull (15\%). The bleeding from middle meningeal arteries collects and develops the hematoma between the skull and dura, this is known as an extradural or epidural hemorrhage, which develops as the space-occupying lesion. This can develop immediately after an accident or after sometime. $^{1,8}$

The signs determined on clinical examination are less accurate indicators for intracranial injury. A significant number of patients with intracranial injuries can be diagnosed by using radiographic imaging of asymptomatic patients with noteworthy hematomas on the scalp. Asymptomatic patients without major scalp hematoma can be managed safely without any radiographic imaging. ${ }^{9,10}$ One study conducted in Peshawar found that in patients presenting with a head injury, skull fracture was found in $31.09 \%$ of cases on x-ray skull, and among them $8.53 \%$ had extradural hematoma on CT scan. ${ }^{11}$

The rationale of this study was to assess the frequency of skull fracture on x-ray skull in patients presenting with a head injury and extradural hematoma in patients with a skull fracture. Literature showed that in patients with skull fractures, the chances of extradural hematoma are low. But this was only a study conducted in Pakistan and no more evidence has been reported in this regard. So we conducted this study to find the extent of the problem, as, in routine, the chances of extradural hematoma are higher among patients with a skull fracture. This would improve our practice and we would be able 
to implement the early screening of patients with skull injury to predict extradural hematoma and early management could be started.

\section{MATERIAL \& METHODS}

\section{Study Design \& Settings}

A descriptive case series was conducted at the Department of Neurosurgery, RMU and allied Hospital, Rawalpindi for 6months, i.e. from 2-42017 to $1-10-2017$.

\section{Sample Size \& Technique}

WHO sample size calculator was used to determine the minimally required sample size $(n=322)$ as follows: confidence level: 95\%; anticipated population proportion: $0.298^{10}$ and absolute precision: 0.05 . A non-Probability, Consecutive sampling was considered.

\section{Inclusion Criteria}

Patients included with ages between $16-80$ years of either gender presenting with head injury (on clinical examination) in last 24 hours with confirmed fracture of the skull based on x-ray skull.

\section{Exclusion Criteria}

The patients with bleeding disorders, vascular malformations of dura mater, post-surgical extradural hematoma were excluded.

\section{Data Collection}

322 patients fulfilling the selection criteria were enrolled in the study from Emergency Ward. Informed verbal consent was obtained from attendants of each patient. Demographic details were also noted. Patients with head injury having skull fracture undergone a CT scan for assessment of presence or absence of extradural hematoma. It was defined as the accumulation of blood between the inner table of the skull and Dura mater of the brain detected on the CT scan brain after the admission of the patient. Skull fracture was labeled if there was a break in the continuity of skull bone detected on the X-ray skull. CT scan was done by a single senior radiologist for all patients. All information was recorded in the structured proforma. The data was entered and analyzed through SPSS version 24. Permission and approval of the study were sought from the hospital ethics committee for conducting the study. All trauma patients presenting to ER, fulfilling the inclusion criteria were enrolled in this study and reviewed by a senior neurosurgeon for appropriate management.

\section{Statistical Calculations/Data Analysis}

For descriptive statistics, the frequencies and mean values were calculated. For inferential statistics, Chi-Square was used for finding correlations among variables.

\section{RESULTS}

\section{Age \& Gender Distributions}

Mean age of patients in this study was $41.31 \pm$ 14.67 years. Among the patients 259 (80.4\%) were male and 63 (19.6\%) were females (Table 1).

\section{Duration and Pattern of Injury}

The mean duration of injury of the patients was $6.37 \pm 3.40$. Linear type of injury was observed in $65(20.2 \%)$ cases, simple type in $62(25.5 \%)$ cases, depressed type in 100 (31.1\%) cases while the compound type of skull fracture in 75 (23.3\%) (Table 2). The fracture was present at frontal in 57 (17.7\%) cases, parietal site in 111 (34.5\%) cases, temporal site in 90 (28\%) cases and occipital site in $64(19.9 \%)$ cases (see Table 3$)$. The extradural hematoma was diagnosed in 104 (32.3\%) patients (Figure 1). 
Table 1: Demographics of Patients $(n=322)$.

\begin{tabular}{lc|} 
Age (Years) & $41.31 \pm 14.67$ \\
Male & $259(80.4 \%)$ \\
Female & $63(19.6 \%)$ \\
Duration of Injury (Hours) & $6.37 \pm 3.40$ \\
\hline
\end{tabular}

Table 2: Type of Skull Fractures.

\begin{tabular}{|lr} 
Type of Skull Fracture & \\
Linear & $65(20.2 \%)$ \\
Simple & $62(25.5 \%)$ \\
Depressed & $100(31.1 \%)$ \\
Compound & $75(23.3 \%)$ \\
\hline
\end{tabular}

Table 3: Site of Skull Fracture.

\begin{tabular}{lc|} 
Site of Skull Fracture & \\
Frontal & $57(17.7 \%)$ \\
Parietal & $111(34.5 \%)$ \\
Temporal & $90(28 \%)$ \\
Occipital & $64(19.9 \%)$ \\
\hline
\end{tabular}

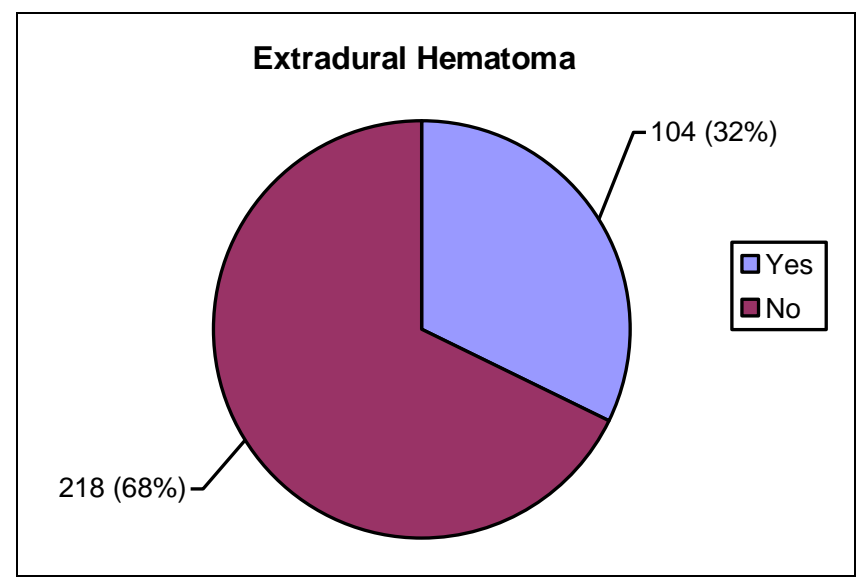

Figure 1: Frequency of extradural hematoma.

\section{Frequency of Hematoma}

Younger patients had a higher frequency of extradural hematoma i.e., 16 - 32 years: $62.5 \%$, 33 - 48 years: $30.8 \%$ and 49 - 64 years: $6.7 \%$. Among male patients, frequency of extradural hematoma was higher as compared to female patients i.e. $77.9 \%$ vs. $22.1 \%$. $37.5 \%$ of patients presenting within 4 hours of injury had an extradural hematoma, $33.7 \%$ of patients between
5 - 8 hours of injury had and extradural hematoma and the percentage of patients presenting 9 to 12 hours of injury with and EDH was $28.8 \%$. 23 patients with an EDH had a linear fracture, 26 had a simple fracture, 32 had a depressed fracture and 23 had a compound fracture. Patients with a fracture on the parietal site $(52.9 \%)$ followed by the temporal site $(23.1 \%)$ and frontal side (14.4\%) had the highest frequency of extradural hematoma.

Table 4: Frequency of extradural hematoma in relation to effect modifiers.

\begin{tabular}{|c|c|c|c|}
\hline & \multicolumn{2}{|c|}{ Extradural Hematoma } & \multirow[b]{2}{*}{ Total } \\
\hline & $\begin{array}{l}\text { Present } \\
(n=104)\end{array}$ & $\begin{array}{c}\text { Absent } \\
(n=218)\end{array}$ & \\
\hline \multicolumn{4}{|l|}{ Age (years) } \\
\hline $16-32$ & $65(62.5 \%)$ & $55(25.2 \%)$ & 82 \\
\hline $33-48$ & $32(30.8 \%)$ & $51(23.4 \%)$ & 77 \\
\hline $49-64$ & $7(6.7 \%)$ & 112 (51.4\%) & 163 \\
\hline \multicolumn{4}{|l|}{ Gender } \\
\hline Male & 81 (77.9\%) & 178 (81.7\%) & 259 \\
\hline Female & $23(22.1 \%)$ & $40(18.3 \%)$ & 63 \\
\hline \multicolumn{4}{|c|}{ Duration of Injury } \\
\hline 1-4 Hours & 39 (37.5\%) & $71(32.6 \%)$ & 110 \\
\hline 5-8 Hours & 35 (33.7\%) & $81(37.2 \%)$ & 116 \\
\hline 9-12 Hours & $30(28.8 \%)$ & 66 (30.3\%) & 96 \\
\hline \multicolumn{4}{|c|}{ Type of Skull Fracture } \\
\hline Linear & $23(22.1 \%)$ & 42 (19.3\%) & 65 \\
\hline Simple & $26(25 \%)$ & $56(25.7 \%)$ & 82 \\
\hline Depressed & $32(30.8 \%)$ & 68 (31.2\%) & 100 \\
\hline Compound & $23(22.1 \%)$ & 32 (23.9\%) & 75 \\
\hline \multicolumn{4}{|c|}{ Site of Fracture } \\
\hline Frontal & 15 (14.4\%) & 42 (19.3\%) & 57 \\
\hline Parietal & 55 (52.9\%) & 56 (25.7\%) & 111 \\
\hline Temporal & 24 (23.1\%) & 66 (30.3\%) & 90 \\
\hline Occipital & 10 (9.6\%) & $54(24.8 \%)$ & 64 \\
\hline
\end{tabular}

Table-5: Correlation among age, gender, duration of injury, type of skull fracture and site of fracture with presence of an extradural hematoma

\begin{tabular}{|lcc|} 
& $\begin{array}{c}\text { Extradural } \\
\text { Hematoma } \\
(\mathbf{n}=\mathbf{1 0 4}) \\
\mathbf{p} \text {-value }\end{array}$ & $\begin{array}{c}\text { Significance/ } \\
\text { Non-Significance } \\
(\mathbf{p} \leq \mathbf{0 . 0 5})\end{array}$ \\
Age & 0.000 & Significant \\
Gender & 0.426 & Non-significant \\
Duration of injury & 0.674 & Non-significant \\
Type of skull fracture & 0.942 & Non-significant \\
\hline
\end{tabular}

Pak. J. of Neurol. Surg. -2021 - 25 (1): 49-56. 
Site of fracture: (Parietal) $\quad 0.000 \quad$ Significant

Table 3 showed that using Chi-Square there was a highly significant relationship between the age of the patients and the presence of an extradural hematoma ( $p=0.000)$. There was no statistically significant relation between gender, duration of injury, and type of fracture when tested with the presence of an extradural hematoma ( $p=0.426,0.674,0.942$, respectively). A highly significant relation was found among the site of fracture (parietal bone fracture) and the presence of an extradural hematoma ( $p=0.000)$.

\section{DISCUSSION}

Traumatic injuries to the head are one of the leading causes of unnatural death and disability in adults. Many types of head injuries are pliable to the neurosurgical intervention, and better outcomes can be achieved in patients who receive quick treatment after traumatic extra-axial cerebral mass abrasions, including extradural hematoma and subarachnoid hemorrhage. ${ }^{12}$ Intracranial hematoma is deliberated as a very serious complication after a head injury, which necessitates the fast diagnosis and quick treatment or intervention. But in developing countries, including Pakistan, where the facility of CT scan is not widely available, the diagnosis can be predictable by taking the clinical history and the detection of skull bone fractures on plain $x$ ray films. ${ }^{13}$

In this study frequency of extradural hematoma in patients with skull fractures was 32.3\%. Two local studies from Pakistan one from Ayub Medical College and the other from Peshawar reported the frequency of extradural hematoma in patients with head injury as $29.8 \%$ and $38.88 \%{ }^{12,}{ }^{14}$ Another study from Peshawar by Rehman et al found that $8.53 \%$ of patients had extradural hematoma who presented with a head injury. ${ }^{11}$ In another study by Perep et al and colleagues the incidence of extradural hematoma and intraparenchymal hemorrhage is $22 \% .^{15}$

In this study, the frequency of extradural hematoma was higher as compared to the frequency in the above-mentioned studies except for the one study from Peshawar in which the frequency was $38.88 \%$. The higher frequency of extradural hematoma can be explained on the basis that among them $52.9 \%$ of patients' fracture site was parietal and in $23.1 \%$ of patients the fracture site was temporal. Statistically significant relationships were found out between age and presence of an extradural hematoma and the parietal bone fracture and presence of a hematoma ( $p=0.000$ in both the correlations). The findings showed that there was a negative relationship between the age of patients and an extradural hematoma. Incidence of an EDH in younger age group (16 - 32 years) was found higher as compared to the other ages. Similarly, parietal bone fracture showed a highly significant incidence of $\mathrm{EDH}$.

Roka et al., observed that the frequency of extradural hematoma in patients of age $11-40$ years was very high i.e. $83 \%$ which was very high as compared to what we observed in our study (62.5\% in age $16-32$ years). ${ }^{17}$ Ozkan et al. also observed that the maximum number of patients who develop extradural hematoma in the age range between $10-40$ years. ${ }^{18}$ Aurangzeb also reported that the frequency of extradural hematoma was $40 \%$ in patients aged between 16 - 35 years, while $36.8 \%$ had an age range between $36-60$ years. ${ }^{14}$

Chattopadhyay et al. observed that the frequency of extradural hematoma has been increased after head trauma because of the fact that in several cases there is blunt force effect that direct effect on temporal and parietal areas, which causes the fracture of the skull bones, which eventually leads to rupture of brain blood vessels in the epidural space. ${ }^{16}$ In this study, frequency of extradural hematoma was 
significantly higher in the younger age group i.e. $16-32$ years $(62.5 \%$, $p$-value $=0.000)$.

Serdar et al. found that in patients presented with a head injury, the frequency of extradural hematoma in the occipital skull fractures was $11 \%$. But Paiva et al. observed found that the frequency of extradural hematoma associated with a parietal skull fracture was $61 \%$ and Aurangzeb also showed a similar finding i.e. $50 \%,{ }^{14,20}$ while in our study, the frequency of extradural hematoma was $32.3 \%$ in traumatic head injuries. In this study frequency of extradural hematoma skull fracture in patients with a head injury is $23.1 \%$ which is closely coincide with the findings of Aurangzeb A et al (24\%), ${ }^{14}$ Igun et al. $(34 \%)^{21}$ and Rehman et al (35.71\%). ${ }^{9}$

As per findings of Ullah et al. extradural hematoma was common in the age group of 21 40 years i.e. $35.42 \%$ and less common in the age of > 40 years i.e. $11.45 \% .{ }^{12}$ Findings of Roka et al, Aurangzeb et al. andUllah et al. regarding the higher incidence of extradural hematoma in the younger age groups are in line with the findings of this study. The overall frequency of female patients was lower as compared to male patients i.e. $19.6 \%$ vs. $80.4 \%$. Among female patients frequency of extradural hematoma was lower as compared to male patients. Similar findings were reported by Aurangzeb, et al and Ullah et al. Nath et al. ${ }^{12,14}$ documented the ratio of $4: 1$ for males: females for extradural hematoma after a traumatic head injury with a skull fracture. ${ }^{19}$ As males have four times more chances of extradural hematoma after head trauma than females, as a consequence of more exposure of the males to outdoor activities and in traffic as compared to the females.

Patients with skull fractures must be referred to the health care center where neurosurgical facilities are available without any delay, even in the absence of any significant head injury but suspicion of the hematoma. The cases without skull fracture, but in the conscious state must be observed carefully, highly suspecting the development of an extradural hematoma.

\section{CONCLUSION}

Results of this study showed a low frequency of extradural hematoma in patients who presented with a head injury. Still, any patient suspected of head injury leading to skull fractures must be examined on CT scan to avoid and timely detect the intracranial bleeding in order to avert the complications and mortality after a traumatic head injury.

\section{REFERENCES}

1. Khan AN, Turnbull I, MacDonald S, Al-Okaili R. Imaging in Skull Fractures, 2011.

2. Desikan RS, Chen JY. Imaging of temporal bone trauma. Operative Techniques in OtolaryngologyHead and Neck Surgery, 2014; 25 (1): 110-7.

3. Kennedy TA, Avey GD, Gentry LR. Imaging of temporal bone trauma. Neuroimaging Clinics of North America, 2014; 24 (3): 467-86.

4. Arrey EN, Kerr ML, Fletcher S, Cox Jr CS, Sandberg DI. Linear nondisplaced skull fractures in children: who should be observed or admitted? Journal of Neurosurgery: Pediatrics, 2015; 16 (6): 703-8.

5. Mishra A, Mohanty S. Contre-coup extradural haematoma: a short report. Neurology India, 2001; 49 (1): 94.

6. Bir SC, Maiti TK, Ambekar S, Nanda A. Incidence, hospital costs and in-hospital mortality rates of epidural hematoma in the United States. Clinical Neurology and Neurosurgery, 2015; 138: 99-103.

7. Duthie G, Reaper J, Tyagi A, Crimmins D, Chumas P. Extradural haematomas in children: a 10-year review. British Journal of Neurosurgery, 2009; 23 (6): 596-600.

8. Raut AA, Naphade PS, Chawla A. Imaging of skull base: Pictorial essay. Indian Journal of Radiology and Imaging, 2012; 22 (4): 305.

9. Dayan PS, Holmes JF, Atabaki S, Hoyle J, Tunik MG, Lichenstein $R$, et al. Association of traumatic brain injuries with vomiting in children with blunt head trauma. Annals of Emergency Medicine, 2014; 63 
(6): 657-65.

10. Mannix R, Bourgeois FT, Schutzman SA, Bernstein $A$, Lee LK. Neuroimaging for pediatric head trauma: do patient and hospital characteristics influence who gets imaged? Academic Emergency Medicine, 2010; 17 (7): 694-700.

11. ur Rehman R, Mushtaq MIUH, Azam F, Khattak A. Skull Fracture on X-ray skull as an indicator of Extradural Hematoma in patients with Head Injury. Pakistan Journal of Neurological Surgery, 2012; 28 (2): 106-9.

12. Ullah W, Ali M, Mehmood K. Spectrum of Surgically Treated Closed Head Injury in Department of Neurosurgery Lady Reading Hospital Peshawar. Pakistan Journal of Neurological Surgery, 2015; 19 (2).

13. Liebeskind DS, Lutsterp $H$, Hogan E. Epidural hematoma. Med Scape; 2013 [cited 2017]; Available from: htp://emedicine.medscape.com/article/1137065overview.

14. Aurangzeb A, Afridi EAK, Khan SA, Muhammad G, Ihsan $A$, Hussain I, et al. Frequency of extradural haematoma in patients with linear skull fracture. Journal of Ayub Medical College Abbottabad, 2015; 27 (2): 314-7.

15. Perel $P$, Roberts I, Bouamra O, Woodford $M$, Mooney J, Lecky F. Intracranial bleeding in patients with traumatic brain injury: a prognostic study.
BMC Emergency Medicine, 2009; 9 (1): 15.

16. Chattopadhyay S, Tripathi C. Skull fracture and haemorrhage pattern among fatal and nonfatal head injury assault victims-a critical analysis. Journal of Injury and Violence Research, 2010; 2 (2): 99.

17. Roka YB, Kumar P, Bista $P$, Sharma GR, Adhikari P. Traumatic posterior fossa extradural haematoma. JNMA; Journal Of The Nepal Medical Association, 2008 Oct. 1; 47 (172): 174-8.

18. Ozkan U, Kemaloglu S, Ozates M, Guzel A, Tatli M. Analyzing Extradural Haematomas: A retrospective clinical investigation. Dicle Tip Dergisi. 2007; 34 (1): 14-9.

19. Nath HD, Rahman $M L$, Rahman $Z$, Uddin $K$, Sahajahan M. Surgical outcome of patients with extradural hematoma at the Department of Neurosurgery in Chittagong Medical College Hospital: A study of 30 patients. Journal of Chittagong Medical College Teachers' Association. 2008; 19 (1): 8-10.

20. Paiva WS, Andrade AFd, Mathias Júnior L, Guirado VMdP, Amorim RL, Magrini NN, et al. Management of supratentorial epidural hematoma in children: report on 49 patients. Arquivos de neuropsiquiatria. 2010; 68 (6): 888-92.

21. Igun $G$. Predictive indices in traumatic intracranial haematomas. East African Medical Journal, 2000; 77 (1).

\section{Additional Information}

Disclosures: Authors report no conflict of interest.

Ethical Review Board Approval: The study was conformed to the ethical review board requirements.

Human Subjects: Consent was obtained by all patients/participants in this study.

\section{Conflicts of Interest:}

In compliance with the ICMJE uniform disclosure form, all authors declare the following:

Financial Relationships: All authors have declared that they have no financial relationships at present or within the previous three years with any organizations that might have an interest in the submitted work.

Other Relationships: All authors have declared that there are no other relationships or activities that could appear to have influenced the submitted work. 


\section{AUTHORS CONTRIBUTIONS}

\begin{tabular}{|l|l|l|}
\hline Sr.\# & Author's Full Name & Intellectual Contribution to Paper in Terms of: \\
\hline 1. & Muhammad Ammad-ul-Haq & Study design, methodology and paper writing. \\
\hline 2. & Ghayur Abbas & Referencing, data calculations, analysis of data and quality insurer. \\
\hline 3. & Anam Ali & Data collection and calculations. \\
\hline 4. & Mamoona Hamid & Analysis of data and interpretation of results etc. \\
\hline 5. & Daniyal Ahmed & Literature review and manuscript writing. \\
\hline
\end{tabular}

